\title{
Editorial
}

\section{Twitter: An educational tool in 140 characters}

Technology and social media are ubiquitous in the educational setting, blogs, wikis, podcasts, ebooks, apps, Twitter, Facebook, Instagram, Linkedin, YouTube, Researchgate; the list of common social media sites and tools used by staff and students at university is almost endless. The way we deliver and receive information is ever changing, students expect to be able to access information where and when they want it and in a user-friendly format. Students today are much more likely to get information from social media sites on their smart phone in a café, than read a book or journal in a library. A recent study reported that $97 \%$ of physiotherapy students now use social medial for educational purposes [1]. For those of us engaged in student education this presents challenges - particularly for those not entirely comfortable with social media. However, the technology also presents opportunities for students; ease of access to high quality information means that it is that much easier to keep up to date with developments and recent research in any particular field. For clinical colleagues engaging in Continuing Professional Development is just a click away!

There is a perception among some that social media is a frivolous waste of time, however, more and more academic colleagues, researchers and clinicians are engaging with social media as a routine part of their professional role. Social media, and in particular Twitter, presents a fantastic opportunity to network and engage in debate and discussion with like-minded colleagues. Twitter presents an opportunity to keep up to date with developments in your area of interest, to connect with colleagues across the globe, to engage with students and to disseminate research findings.

For the uninitiated, Twitter is a social media tool in which the account holder (in my case @ mcveigh_joe) may send or receive short, public messages, or tweets of 140 characteristics or less. Twitter is designed for 'conversation' and to share ideas, as such it is ideal for use as an educational tool. Engagement in the educational process is facilitated by using a media application that learners are interested in and Twitter accounts can easily be set up for an individual class or group of students. Twitter can then be used to 'push' educational content directly to students' mobile devices and there is some evidence that students find this useful and user-friendly [2]. However, it seems prudent that students maintain a separation between professional and personal use of social media and students have expressed the desire that privacy is maintained within the educational context. ${ }^{1}$ Due to the public nature of Twitter, there are limits on how social media can be used by educators and as with all social media it is essential that all users maintain the utmost professional and ethical standards at all times.

There are multiple journals clubs and 'tweet chats' in physiotherapy and healthcare related subjects. Whatever your particular interest you will be able to follow journals or colleagues with similar interests by simply following a hashtag (\#). \#physiotalk, for example, is a regular tweet chat, hosted by physiotherapists in the UK, to support and facilitate discussion about physiotherapy evidence and practice. \#physiotalk has over 11,200 followers from more than 110 countries and 4600 people have used the hashtag \#physiotalk in 36,400 tweets. By any standards this represents significant global engagement by the physiotherapy community. Most conferences will have a specific hashtag to facilitate engagement with those who are unable to attend. The recent Irish Society of Chartered Physiotherapists' annual conference had more than 3000 tweets of the hashtag \#iscpconf15, again representing significant engagement with the wider physiotherapy community. 
For those engaged in research, social media is increasingly being used as a method to recruit participants to research studies [3], in particular it has been used with some success in 'hard to reach' communities [4]. In the past, obtaining the opinions of patients or therapists often involved cumbersome postal surveys $[5,6]$ with their many limitations. Today, opinions can be gleaned almost instantaneously, and while the rigour of using social media for this purpose still has to be fully tested, there is no doubt that social media presents an extremely useful recruitment tool for researchers.

The use of social media in education and professional development is emerging and evolving. The flexibility of the technology can enhance student learning and experience; however, there are confidentiality and privacy issues that need to be recognised. Additionally, the ease of access and amount of information available may encourage 'scanning and skimming' as opposed to deep learning - learning takes time regardless of the technology. Finally, it should be remembered that social media is not primarily about the technology, it is about engagement, debate and discussion. If you haven't already, it's time to join the conversation.

J.G. McVeigh Editor-in-Chief

\section{References}

[1] Maloney S, Moss A, Ilic D. Social media in health professional education: A student perspective on user levels and prospective applications. Adv Health Sci Educ Theory Pract. 2014;19(5):687-97.

[2] Bahner DP, Adkins E, Patel N, Donley C, Nagel R, Kman NE. How we use social media to supplement a novel curriculum in medical education. Med Teach. 2012;34(6):439-44.

[3] O'Connor A, Jackson L, Goldsmith L, Skirton H. Can I get a retweet please? Health research recruitment and the Twittersphere. J Adv Nurs. 2014;70(3):599-609.

[4] Martinez O, Wu E, Shultz AZ, Capote J, López Rios J, Sandfort T, Manusov J, Ovejero H, Carballo-Dieguez A, Chavez Baray S, Moya E, López Matos J, DelaCruz JJ, Remien RH, Rhodes SD. Still a hard-to-reach population? Using social media to recruit Latino gay couples for an HIV intervention adaptation study. J Med Internet Res. 2014;16(4):e113.

[5] McVeigh JG, Millar A, Hurley DA, Basford JR, Baxter GD. Patients' perceptions of exercise therapy in the treatment of fibromyalgia syndrome. Musculoskeletal Care. 2003;1:98-107.

[6] McVeigh JG, Archer S, Hurley D, Baxter GD, Basford JR. Physiotherapy management of fibromyalgia syndrome: A survey of practice in Northern Ireland. Int J Ther Rehabil. 2004;11:71-7. 